\title{
Early Realized Gains for Two-cycle Selection for Black Spruce and Their Implications for Testing Effort Allocation
}

\author{
By Y. H. WENG ${ }^{*}$
}

(Received $19^{\text {th }}$ July 2010)

\begin{abstract}
Deployment of improved black spruce (Picea mariana (Mill.) B.S.P.) seedlots in New Brunswick (NB) is a standard silvicultural practice. Most plantations have been established using elite-stand seedlots in the 1980s, firstgeneration seedling seed orchard seedlots in the 1990s and thereafter second-generation clonal seed orchard seedlots. A large-plot realized gain test was established at six sites in NB to provide estimates of actual gains from planting these improved seedlots. The test compared four improved seedlots, representing seedlots collecting from an elite stand, a first-generation seed orchard, two second-generation orchards and a mix of eight elite full-sib families identified in second-generation testing populations, with one unimproved checklot. This paper presents height measurements taken on trees at age 5. Results indicate that realized genetic gains from two-cycle selection and breeding are reasonably high and, in general, the more improved the seedlot, the higher the gain. Planting the elite-stand or the first-generation orchard seedlot would produce a gain of about $10 \%$ (relative to the checklot) in 5-yr height and an additional $5.8 \%$ gain could be obtained from planting the second-generation orchard seedlot. Even higher gain could be obtained via the deployment of the elite full-sib families, which was estimated to be about $8.6 \%$ more than the deployment of the second-generation orchard seedlot. While the realized gain varied with site, the ranking of gain achieved for the different seedlots was similar between sites. The above information was further used to optimize testing efforts for realized gain tests. To detect a typical gain of 5 to $10 \%$ at a significance level of 0.05 with a predetermined power of 0.80 , each test should include 5 to 10 blocks per site (the number of sites is fixed at 4 ) or 4 to 6 sites (the number of blocks per site is fixed at 6) paired with planting 36 to 49 trees per plot. These approximate numbers of sites and blocks per site should be modified, depending on the interactions of seedlot with site and with block within site.
\end{abstract}

Key words: tree improvement, realized gain test, power analysis, seedlot deployment.

\section{Introduction}

Tree improvement activities for black spruce (Picea mariana (Mill.) B.S.P.) in New Brunswick (NB), Canada, started in the early 1970s. The program started with identifying elite-stand seedlots (EliteStand), which provided an interim seed supply for reforestation in the 1980s. Following that, a strategy, following selection for

\footnotetext{
*) Contact adress: Y. H. Weng. New Brunswick Department of Natural Resources, Kingsclear Forest Nursery, Island View, NB, Canada, E3E 1G3. Telephone 506-444-5125, Fax 506-4444917. E-Mail: Yuhui.Weng@gnb.ca.
}

recurrent general combining ability (FOWLER, 1986), was applied. In its first-generation program, plus-tree selections were made in wild stands, followed by the establishment of first-generation seedling seed orchards $\left(\mathrm{SO}_{1 \mathrm{st}}\right)$ and family tests. A total of 39 ha $\mathrm{SO}_{1 \text { st }}$ was established in the early 1980s and the orchards provided all seed for reforestation in the $1990 \mathrm{~s}$. Selection of trees for the second-generation program started in 1989 and a total of 12 ha second-generation clonal seed orchards $\left(\mathrm{SO}_{2 \text { nd }}\right)$ was established. The $\mathrm{SO}_{2 \text { nd }}$ have been starting to provide most (>80\%) seed for reforestation since 2004 . Height growth was the primary target in all selections.

Whereas theoretical gains from planting these improved seedlots have been predicted based on genetic tests using small plot sizes, information regarding actual gains when they are planted in operational plantations, called realized gain, is still very limited. Demonstration of realized gains requires the establishment of large-plot genetic tests, called realized gain tests, so that improved and unimproved commercial seedlots are compared in paired environments small enough to minimize environmental effects yet large enough to reflect stand dynamics (Weng et al., 2008). Only a few studies have utilized large-plot design to explore realized gains and available information can be found in radiata pine (P. radiata D. Don) (EldRIDGE, 1982; CARSON et al., 1999), slash pine (P. elliottii Englem var. elliottii) (VERGARA et al., 2004), coastal Douglas-fir (Pseudotsuga menziesii) (ST. ClaIR et al., 2004; STOEHR et al., 2010; YE et al., 2010), jack pine (P. banksianna Lamb.) (WENG et al., 2008), white spruce (Picea glauca [Moench] Voss) and black spruce (WENG et al., 2010). These studies provide the evidence of efficiency in improving tree growth through one-cycle selection. To our knowledge, realized gains for seedlots collected from more advanced generations have not been reported so far, even if many programs have reached their third and more advanced generations. Demonstration of realized gains from tree improvement activities is important for planning sustainable forest management plans and for continued funding of breeding programs.

In NB, a typical realized gain test usually includes 4 sites, 6 blocks per site and 64 trees per plot, but only the 36 interior trees are measured. This allocation of testing effort is based more on breeders' experience than on scientific basis. Confusing results were reported in tests with such an allocation: gains of improved seedlots relative to the unimproved checklot were substantial but statistically non-significant (WENG et al., 2008; 2010), very likely a result of a low power level. Thus, a sensitivity analysis on how testing effort allocation, i.e., numbers of sites (n_site), blocks per site (n_block), and trees 
per plot (n_tree), affects the power for a comparison between improved and unimproved seedlots is important and helpful in guiding establishment of future realized gain tests. ST. CLAIR et al. (2004) did a power analysis to investigate the required replicate number for a gain test using the pre-determined desired power $(=0.8)$, treatment differences of interest (gains), magnitude of random error and allowable $\alpha$ level. In their power calculation, other random effects, i.e., $\mathrm{G} \times \mathrm{E}$ interaction, were not considered. Furthermore, they did not investigate how to allocate the numbers of replicates into n_site and n_block. In tree improvement, mixed linear models are often used in data analysis and perhaps should be applied to this issue.

The New Brunswick Tree Improvement Council (NBTIC) initiated a realized gain test of black spruce in 2003 with the long-term objective to test productivity difference between improved and unimproved seedlots at rotation age. The objectives of this study were to provide some insight into the mean and variability of early realized gains from two-cycle selection and breeding, which were then used to determine approximate testing effort distribution for future realized gain tests using the power analysis.

\section{Materials and Methods}

\section{Realized gain test}

A realized gain test was established in 2003 to demonstrate realized gains in growth through tree improvement activities. Four improved seedlots and a checklot were included:

- EliteStand represents a superior stand seedlot, consisting of a bulk seed harvest from the Westmuzrolle $\left(46^{\circ} 10^{\prime} \mathrm{N}, 65^{\circ} 09^{\prime} \mathrm{W}\right)$ stand. This seedlot was identified as one of the best seedlots in height growth in early stand tests and was recommended for reforestation in NB (NBTIC, 1977).

$-\mathrm{SO}_{1 \mathrm{st}}$ was a mixed cone collection in 1994 from a first-generation seedling seed orchard located at Bettsburg, NB $\left(46^{\circ} 26^{\prime} \mathrm{N}, 66^{\circ} 15 \mathrm{~W}\right)$. The orchard was established in 1980 using seed collected from phenotypicallyselected plus trees across NB and was genetically rogued in 1990 based on their parental breeding values of height predicted from the first-generation family tests with $52 \%$ of the original families removed (110 families remained after rogueing).

$-\mathrm{SO}_{2 \text { nd }}$ originated from cones collected in 2000 from second-generation clonal orchards planted at both Kingsclear $\left(45^{\circ} 57^{\prime} \mathrm{N}, 66^{\circ} 48^{\prime} \mathrm{W}\right)$ and Parkindale $\left(45^{\circ} 52^{\prime} \mathrm{N}\right.$, $\left.65^{\circ} 3^{\prime} \mathrm{W}\right)$. The orchards were established using the best trees identified in the first-generation family tests based on their height growth and stem straightness. Both orchards included more than 40 clones and were established in 1990.

- EliteFam ${ }_{2 \text { nd }}$ represents a mixed seed collection of eight elite full-sib families. Controlled pollinations were made on trees which were selected from the first-generation family tests and their offspring were tested in progeny tests. These families were identified in the progeny tests for their good height growth. This seedlot essentially belongs to the same generation as the $\mathrm{SO}_{2 \text { nd }}$ in terms of tree improvement.

- Checklot represents an average-performing stand seedlot, consisting of a bulk seed harvest from Taylor Brook $\left(47^{\circ} 20^{\prime} \mathrm{N}, 66^{\circ} 05^{\prime} \mathrm{W}\right)$, NB. This seedlot showed an average performance in height growth in early stand tests (NBTIC, 1977) and has been consistently used as the checklot in all NBTIC black spruce genetic tests.

The seedlings of all the seedlots were grown in the Kingsclear tree improvement greenhouse $\left(45^{\circ} 57^{\prime} \mathrm{N}\right.$, $\left.66^{\circ} 48^{\prime} \mathrm{W}\right)$. The seed was sown in Feb. 2003 in Can-Am \# 3 containers. The greenhouse was maintained at $21^{\circ} \mathrm{C}$ during the day and $15^{\circ} \mathrm{C}$ at night. A soluble liquid fertilizer schedule was applied to the 3:1 peat: vermiculite growing medium once per week. When the seedlings were 18-weeks old, they were moved out to a shaded area. The realized gain test was then planted in July when the seedlings were 6-months old.

The realized gain test was planted at six sites: FRA1, FRA2, JDI1, JDI2, UPM1, and UPM2 (Table 1). These sites occur in four ecological zones (Zelanzy 2007), which represent the main reforestation regions for black spruce in NB. A complete randomized block (RCB) design of six blocks and large square plots was used at each site. Each plot consisted of 64 trees of a seedlot planted in an 8 row $\times 8$ column at a spacing of $2 \times 2 \mathrm{~m}$. As no border trees were planted around the plots, only the inside 36 trees $(6$ row $\times 6$ column $)$ were measured to reduce competition between seedlots. Available data in this study included survival and individual tree height at age 5, referred to in this study as Surv5 and HT5, respectively.

\section{Data analysis}

The validity of the data was first inspected using the SAS univariate/plot procedure (SAS Institute Inc. 1990). Less than $0.2 \%$ (11 observations) of the data were detected as outliers (those located outside three interquartile ranges) and removed from further analyses. Statistical analysis on Surv5 was performed using SAS PROC GLIMMIX (LITTELL et al., 2006) using the following model:

$$
\eta_{i j k}=\mu+T_{i}+B_{j(i)}+S_{k}+T S_{i k}+\varepsilon_{i j k}
$$

where $\eta_{i j k}$ is the ratio of the number of living trees over the total number of trees of the $k^{\text {th }}$ seedlot observed in the $j^{\text {th }}$ block within the $i^{\text {th }}$ site, $\mu$ is the overall mean, $T_{i}$ is the effect of the $i^{\text {th }}$ site, $B_{j(\mathrm{i})}$ is the effect of the $j^{\text {th }}$ block within the $i^{\text {th }}$ site, $S_{k}$ is the effect of the $k^{\text {th }}$ seedlot, $T S_{i k}$ is the interaction effect between the $i^{\text {th }}$ site and $k^{\text {th }}$ seedlot and $\varepsilon_{i j k}$ is the random error. The pseudo-likelihood method (LITTELL et al., 2006), which is based on restricted maximum likelihood (REML) estimation in linear models, and the logit link function were used to calculate Surv5. Analysis of variance on HT5 was performed using the REML option of the SAS PROC Mixed procedure (LITTELL et al., 2006) using the following model:

$$
Y_{i j k l}=\mu+T_{i}+B_{j(i)}+S_{k}+T S_{i k}+B S_{j k(i)}+\varepsilon_{i j k l}
$$

where $Y_{i j k l}$ is HT5 of the $l^{\text {th }}$ tree of the $k^{\text {th }}$ seedlot planted in the $j^{\text {th }}$ block within the $i^{\text {th }}$ site, $B S_{j k(i)}$ represents the 
Table 1. - Site information for the 2003 black spruce realized gain test in New Brunswick.

\begin{tabular}{llllll}
\hline Site & Long./Lat. & Rainfall & GDI $^{\mathrm{b}}$ & FR $^{\mathrm{e}}$ & Soil \\
\hline FRA1 & $66^{\circ} 55^{\prime} / 46^{\circ} 25^{\prime}$ & $475-525$ & $1400-1600$ & $\mathrm{CL}$ & low-fertile shallow stony soil \\
FRA2 & $68^{\circ} 13^{\prime} / 47^{\circ} 27^{\prime}>500$ & $1400-1600$ & $\mathrm{CL}$ & moderate-fertile compact tills \\
JDI $\quad 67^{\circ} 00^{\prime} / 46^{\circ} 37^{\prime}$ & $425-450$ & $1650-1700$ & VL & moderate-fertile compact tills \\
JD12 $65^{\circ} 25^{\prime} / 45^{\circ} 58^{\prime}$ & $425-450$ & $1600-1750$ & VL & most-fertile alluvial soil \\
LPM1 $66^{\circ} 10^{\prime} / 47^{\circ} 34^{\prime} 400-500$ & $1450-1550$ & NU & moderate-fertile stony soil \\
LPM2 $65^{\circ} 26^{\prime} / 47^{\circ} 20^{\prime} 350-400$ & $1400-1600$ & EL & low-fertile compact soil
\end{tabular}

\footnotetext{
a May to September rainfall $(\mathrm{mm})$.

${ }^{\mathrm{b}}$ Annual growing degree days above $5^{\circ} \mathrm{C}$.

c ER, Ecological Region: NU, Northern Uplands; CU, Central Uplands; VL, Valley Lowlands; and EL, Eastern Lowlands.
}

interaction effect between the $j^{\text {th }}$ block and the $k^{\text {th }}$ seedlot within the $i^{\text {th }}$ site, and remaining terms are defined as in the model [1]. All terms in both models were treated as random except the overall mean and seedlot factor $\left(S_{k}\right)$. The least square means (LSM) for seedlots and their significance in the difference between seedlots were predicted using the ESTIMATE option. Realized gain in HT5 was estimated as the LSM difference between the Checklot and the improved seedlot and was subsequently expressed as a percentage of the Checklot mean. Note that here and elsewhere in the text, except where otherwise indicated, the term significant refers to the $5 \%$ significance level $(\operatorname{Pr}<0.05)$.

Due to the fact that the site-to-site variation was substantial and the TS interaction was non-significant $(P r=0.35)$, a further analysis was done to take these issues into account. First, data was analyzed by fitting the actual residual variance for each site to model [2] using ASReml (GILMOUR et al., 2002). The estimated variance components were very similar to those found without adjusting site heterogeneity. Second, the nonsignificant TS interaction was removed from the model; it improved the denominator degree of freedom for testing seedlot effect (from 20 to 135) and then increased the statistical power, but also did not change variance component estimates. Thus, to simplify the presentation of results and to evaluate the effects of TS interaction on testing effort allocation (see below), only the results of the analysis without adjusting site-to-site variation and pooling are presented.

Power calculation is useful in planning realized gain tests. Statistical power is defined as the probability of rejecting the null hypothesis $\left(\mathrm{H}_{0}\right.$ : no significant difference in growth between treatments). If $\mathrm{H}_{0}$ is true then the associated $F$ statistic has a central $F$ distribution with two parameters, the numerator and denominator degrees of freedom. When $\mathrm{H}_{0}$ is false, the associated $F$ statistic has a noncentral $F$ distribution that depends upon the numerator and denominator degrees of freedom. In this case, the noncentrality parameter may reflect the magnitude of the treatment effect (KONONOFF and HANFORD, 2006). Thus, power for mixed models can be specified as a function of the probability of the Type I error, sample size (n_site, n_block, and n_tree), numerator and denominator degrees of freedom, treatment differences, and variance component estimates (LITTELL et al., 2006). A SAS program (available from the author) was developed to calculate power for mixed models following the procedure outlined in STROUP (1999) and in KONONOFF and HANFORD (2006). The procedure includes four steps: (1) create a data set with the structure of the design to be assessed (i.e., setting $\mathrm{H}_{0}$ ); (2) run PROC Mixed with the variance and covariance components set at the anticipated values; (3) generalize F-statistics; and (4) use SAS function statements for the $F$ distribution to compute power. As tree breeders are interested in the progress between generations, the $\mathrm{H}_{0}$ in this study were deliberately selected: no significant difference in growth between the $\mathrm{SO}_{1 \text { st }}$ and Checklot and between $\mathrm{SO}_{2 \text { nd }}$ and $\mathrm{SO}_{1 \mathrm{st}}$. The variance component estimates for HT5 obtained in this study were used as the baseline scenario. The sensitivity of n_site, n_block, and n_tree on power was investigated by varying one number at a time while keeping the other two constant.

\section{Results and Discussion}

\section{Five-year survival (Surv5)}

The average Surv5 pooled over sites and seedlots was $92 \%$. Surv5 varied significantly from site to site $(\operatorname{Pr}<0.01)$, was relatively low at two sites $(<88 \%)$ within the Central Uplands, but high $(>91 \%)$ and comparable among the other sites. The severe competition with weeds may partly explain the low Surv5 at the FRA sites. There was no significant difference among seedlots in site-combined Surv5, with a range of 91 to $93 \%$ (Table 2). The differences in Surv5 among seedlots were significant in four of the six sites, but no seedlots showed consistently low or high Surv5 in all sites (Table 2). Overall, these Surv5 were high and comparable in 
Table 2. - Least square means for seedlots and significance between seedlots for 5-yr survival (in \%) by site and across sites.

\begin{tabular}{llllll}
\hline Site & Elitelam & $\mathrm{SO}_{2 \mathrm{nd}}$ & $\mathrm{SO}_{1 \mathrm{sl}}$ & LlitcStand & Checklot \\
\hline FRA1 & $88 \mathrm{a}$ & $86 \mathrm{a}$ & $86 \mathrm{a}$ & $85 \mathrm{a}$ & $82 \mathrm{a}$ \\
FRA2 & $82 \mathrm{a}$ & $72 \mathrm{~b}$ & $77 \mathrm{ab}$ & $79 \mathrm{ab}$ & $79 \mathrm{ab}$ \\
JDI1 & $94 \mathrm{a}$ & $92 \mathrm{a}$ & $90 \mathrm{ab}$ & $85 \mathrm{~b}$ & $93 \mathrm{a}$ \\
JDI2 & $93 \mathrm{a}$ & $92 \mathrm{a}$ & $98 \mathrm{~b}$ & $90 \mathrm{a}$ & $95 \mathrm{ab}$ \\
LPM1 & $96 \mathrm{a}$ & $94 \mathrm{a}$ & $96 \mathrm{a}$ & $97 \mathrm{a}$ & $95 \mathrm{a}$ \\
LPM2 & $95 \mathrm{a}$ & $97 \mathrm{ab}$ & $94 \mathrm{a}$ & $99 \mathrm{~b}$ & $97 \mathrm{ab}$ \\
Across-sitc & $93 \mathrm{a}$ & $91 \mathrm{a}$ & $92 \mathrm{a}$ & $91 \mathrm{a}$ & $92 \mathrm{a}$
\end{tabular}

Note: Means in a row not followed by a common letter differ at the $\operatorname{Pr}<0.05$ level.

value to those observed in a previous realized gain test (WENG et al., 2010) and NBTIC family tests of black spruce.

The testing sites cover four ecological zones and a wide range of test environments in NB (Table 1). The observed Surv5 suggest that all the seedlot seedlings have the ability to establish themselves well in these environments. Of particular interesting, the non-significant difference between improved seedlots and the Checklot provide the evidence that tree selection and breeding does not significantly reduce survival rate. Actually, for some species, seedlots collected from seed orchards might have high genetic diversity, resulting in higher survival than unimproved stand seedlots (WENG et al., 2008).

\section{Five-year height growth (HT5) and realized gains}

Table 3 presents the results of the site-combined analysis of variance on HT5. The average HT5 pooled over sites and seedlots was $127 \mathrm{~cm}$. The site effects were significant; trees were tallest at JDI2 $(147 \mathrm{~cm})$ and shortest at UPM2 $(95 \mathrm{~cm})$. Differences in soil fertility, precipitation and annual degree days (Table 1) may explain some of these growth differences. The slow growth for the UPM2 was also due to the severe competition with weeds. The block effects were significant, suggesting that blocking is effective for this test. The interaction of seedlot was significant with block within site (BS) but non-significant with test site (TS). Since the BS interaction effect was used to test the significance of the TS interaction effect (Table 3); the strong BS effect might mask the effect of the TS interaction. Overall the relative importance of random factors observed in this study was very typical in NB: random error and site were the most important sources of phenotypic variation for early height growth (WENG et al., 2008; 2010).

Differences in HT5 among seedlots were statistically significant (Table 3). The LSM for seedlot, paired-comparison between seedlots and realized gains in HT5 are listed in Table 4. The differences in site-pooled LSM between seedlots were significant except that between

Table 3. - Results of the analysis of variance on height at age 5. Seedlot was treated as fixed and error, site, block with site, and their interactions with seedlot were treated as random. Variance components (VC) for the random factors are also listed.

\begin{tabular}{lllll}
\hline Source of variation & degree of freedom ${ }^{a}$ & $F$ value & $\operatorname{Pr}>F$ & $\mathrm{VC}$ \\
\hline Site (T) & $5,24.6$ & 29.83 & $<0.0001$ & 279.3 \\
Block within T (B) & $30,115.1$ & 2.52 & 0.0002 & 32.8 \\
Seedlot (S) & $4,20.3$ & 22.05 & $<0.0001$ & $\mathrm{na}^{\mathrm{b}}$ \\
TS & $20,115.2$ & 1.11 & 0.3539 & 0 \\
BS & 115,5435 & 3.94 & $<0.0001$ & 86.3 \\
Error & & & & 899.3 \\
\end{tabular}

\footnotetext{
${ }^{\text {a }}$ Degrees of freedom in numerator and denominator for $F$ test.

${ }^{\mathrm{b}}$ Not available.
} 
Table 4. - Least square means for 5-yr height $(\mathrm{cm})$, significance between seedlots and realized genetic gain (\%) by site and across sites.

\begin{tabular}{|c|c|c|c|c|c|}
\hline & F.liteFam ${ }_{2 n d}$ & $\mathrm{SO}_{2 n d}$ & $\mathrm{SO}_{1 \mathrm{it}}$ & FliteStand & Checklot \\
\hline Across sites & $142.8(25.6) \mathrm{a}$ & $131.5(15.7) \mathrm{b}$ & $124.4(9.4) \mathrm{c}$ & $125.2(10.1) \mathrm{ce}$ & $113.7 \mathrm{~d}$ \\
\hline FRA & $135.4(27.0) \mathrm{a}$ & $131.4(23.3) \mathrm{a}$ & $115.0(7.9) \mathrm{b}$ & $114.7(7.6) b$ & $106.6 \mathrm{~b}$ \\
\hline $\mathrm{F} R \wedge 2$ & $148.5(22.7) \mathrm{a}$ & $142.2(17.5) \mathrm{a}$ & $132.8(9.8) \mathrm{a}$ & $142.0(17.4) a$ & $121.0 \mathrm{~b}$ \\
\hline. $\mathrm{D}] 1$ & $151.7(20.4) \mathrm{a}$ & $142.3(21.4) \mathrm{ab}$ & $131.6(12.3\} \mathrm{b}$ & $135.6(15.7) \mathrm{b}$ & $117.2 \mathrm{e}$ \\
\hline$J \mathbf{J} \mid 2$ & $164.2(23.5) \mathrm{a}$ & $152.4(14.6) \mathrm{ab}$ & $142.0 c 6.8, \mathrm{bc}$ & $145,3(9,2) \mathrm{bc}$ & $133.0 \mathrm{c}$ \\
\hline UPMI & $133.9(17.5) \mathrm{a}$ & $122.8(7.7) \mathrm{ab}$ & $124.6(9.3) \mathrm{a}$ & $123.3(8.2) \mathrm{ab}$ & $114.0 \mathrm{~b}$ \\
\hline UPM2 & $96.6(6.2) \mathrm{ka}$ & $102.0(12.1) \mathrm{s}$ & $100.4(10.3) \mathrm{a}$ & $94.1(3.4) \mathrm{a}$ & $91.0 \mathrm{a}$ \\
\hline
\end{tabular}

Note: Means in a row not followed by a common letter differ at the $\operatorname{Pr}<0.05$ level.

the EliteStand and $\mathrm{SO}_{1 \text { st }}$. The across-site realized gains were high and were ranked as: EliteFam ${ }_{2 \text { nd }}>\mathrm{SO}_{2 \text { nd }}>$ EliteStand $\approx \mathrm{SO}_{1 \mathrm{st}}$. Planting the EliteStand or $\mathrm{SO}_{1 \mathrm{st}}$ would produce about $10 \%$ gain, and an additional of $5.8 \%$ gain could be obtained by planting the $\mathrm{SO}_{2 \text { nd }}$. The largest gain was observed for the EliteFam ${ }_{2 n d}$, which was $8.6 \%$ taller than the $\mathrm{SO}_{2 \text { nd }}$. Detecting significant differences between seedlots at a single site was more difficult. Among the six sites, none of them showed significant difference between the EliteStand and $\mathrm{SO}_{1 \mathrm{st}}$ and between the $\mathrm{SO}_{2 \text { nd }}$ and $\mathrm{SO}_{1 \mathrm{st}}$, whereas three sites had significant difference between the $\mathrm{SO}_{1 \mathrm{st}}$ and Checklot. Correspondingly, realized gain varied from site to site but no consistent site-related pattern stood out. Mixed results have been reported in the literature; some studies have found gain to be either independent of or negatively related to site condition (ELDRIDGE, 1982; ANDERSSON et al., 2003; VERGARA et al., 2004), whereas others have reported an increasing trend with better sites (DHAKAL et al., 1996; CARSON et al., 1999; MATZIRIS, 2000; WENG et al., 2008). Despite substantial site-to-site variation in gain, the more improved seedlots in general had higher gain at each site.

Deploying the EliteStand obtained moderate gain in HT5. This seedlot (also known as CAN101) was tested in a previous black spruce realized gain test which was established in 1991 also in NB (abbreviated as 1991 RGT). The observed gain for the EliteStand in the 1991 RGT was $9.1 \%$ in height at age 5 , very similar to this study, but reduced with age to $4.9 \%$ in $15-\mathrm{yr}$ height (WENG et al., 2010).

Currently, seed orchards are the main delivery system for black spruce in NB. Thus, the gains observed in the orchard seedlots have particular interest for tree breeders. The gain from the $\mathrm{SO}_{1 \mathrm{st}}$ in this study was moderate but could be further improved via a second genetic roguing of the seedling seed orchard (i.e., further reducing the 110 remaining families after the first rogueing to 40 families). However, in the 1991 RGT, a seedlot collected from another NBTIC first-generation seedling seed orchard (genetically rogued once) was only $1.8 \%$ taller than the Checklot at age 5, but the corresponding value increased to $3.5 \%$ at age 15 (WENG et al., 2010). Despite the high variation in gain, overall results from these two realized gain tests suggest that a seedling seed orchard procedure with genetic rogueing can be effective for improving tree growth. The high variation in gain is not unexpected; realized gain usually varies from orchard to orchard for the same generation and from year to year for an orchard. This is because realized gains of an orchard seedlot are not only determined by genetic selection but also depend on how well assumptions related to the orchard are met (i.e. no foreign pollen contamination, no inbreeding, and synchronized flowering). Encouraging results for first-generation seed orchards in improving growth have also been reported for other tree species, i.e., radiata pine (CARSON et al., 1999), slash pine (VERGARA et al., 2004), jack pine (WENG et al., 2008), and white spruce (WENG et al., 2010). This study provided the first gain estimate of the second-generation clonal seed orchard seedlot. The additional gain $(5.8 \%$ over the $\left.\mathrm{SO}_{1 \mathrm{st}}\right)$ suggests the efficiency of further improving height growth by establishing advanced generation seed orchards.

One alternative to the seed orchard method is to practice family forestry, i.e., deployment of small numbers of elite half-sib or full-sib families. In the 1991 RGT, WENG et al. (2010) reported that deployment of one elite halfsib family could obtain $25 \%$ more gain in 15 -yr volume per hectare than the first-generation orchard seedlot. Similarly, results in this study suggest that deployment of elite full-sib families could continue to be more effective at delivering gain than the orchard method, a result of the utilization of dominance and more additive genetic variance as well as the avoidance of the orchard-related assumptions. In a study of coastal Douglas-fir in Oregon, ST. CLAIR et al. (2004) reported that deployment of 10 elite families resulted in $6 \%$ taller and $28 \%$ more stem volume at age 5 than the unimproved seedlot. The primary limitation for deploying small numbers of families is the level of economic risk due to limited diversity (McKEAND et al., 2006). The EliteFam ${ }_{2 n d}$ consisted of 8 unrelated full-sib families, which corresponds to a status number of 17 . Tree breeders in NB believe that a status number of 10 is sufficient to minimize the risk due to unpredicted biotic and environmental stresses. Thus, the superiority of the EliteFam ${ }_{2 \text { nd }}$ over $\mathrm{SO}_{2 \text { nd }}$ could be treated as real with a low level of risk. Produc- 
tivity of family forestry varies with the configuration of deployed families in plantations, i.e., planting as pureor mixed-family blocks, which will result in various competition dynamics after crown closure. Experiences in other species have confirmed that certain families perform better in mixtures than in pure blocks and vice versa (STAUDHAMMER et al., 2009). Overall, as tree breeders learn more about the tradeoffs between risk and gain, it is expected that the deployment of elite families would become more attractive for black spruce. Since 2000 , over 94 million full-sib family seedlings of loblolly pine and slash pine have been planted in the southern US (McKEAND et al., 2007).

The observed gains in the present study indicate that progress from the two-cycle selection and breeding is readily achievable for black spruce. However, the realized gains reported here were only five years old, far too early compared with a rotation age of 50 years. The test will be maintained and measured in the future. Although the realized gain tends to decline with age when it is expressed as a percentage, the absolute increase in growth of improved seedlots over checklots has been shown to increase with age (TALBERT, 1981; McKeAND et al., 2006; WENG et al., 2008, 2010). Furthermore, the fast height growth at early stages has biological significance as it helps to establish early advantage in competition over weeds in operational plantations.

\section{Implications for experimental designs of large plot}

Effects of testing effort allocation on the power for comparing the $\mathrm{SO}_{1 \mathrm{st}}$ and Checklot (gain = 10\%) and comparing the $\mathrm{SO}_{2 \text { nd }}$ and $\mathrm{SO}_{1 \text { st }}$ (gain $=5 \%$ ) can be found in Figure 1. For a test of 4 sites and 6 blocks per site, the power increased with increasing the $\mathrm{n}$-tree, but the impact after 36 trees (when gain $=10 \%$ ) or after 49 (when gain $=5 \%$ ) was largely negligible (Figure 1a). It can also be seen from Figure $1 a$ that, to obtain a predetermined power (set throughout this article as 0.80 ), the required n_tree was less than 25 when the gain was $10 \%$, but became unrealistically large when the gain was $5 \%$. Overall, power was quite insensitive to the n_tree, and a n_tree of 36 to 49 seemed to be appropriate for a gain of 5 to $10 \%$. Power improved greatly with increasing the $\mathrm{n} \_b l o c k$ or $\mathrm{n} \_$site (Figures $1 \mathrm{~b}$ and $1 \mathrm{c}$ ). To obtain the predetermined power (0.8), five blocks per site (n_site is fixed at 4 ) or 4 sites (n_block is fixed at 6 ) were required when the difference between seedlots was about $10 \%$, but the corresponding numbers increased to 10 and 7, respectively, when the seedlot difference was $5 \%$. For a given number of replicates (i.e., n_site*n_block=24), planting more sites and fewer blocks per site would be more effective than the vise versa (the power was 0.58 for the combination of n_site $*$ n_block $=4 * 6$, compared to 0.61 for the combination of $6 * 4$ ). Overall results suggest that a large numbers of replicates $(20 \sim 42)$ are required to detect significant differences of 5 to $10 \%$ in height between improved and unimproved seedlots with the predetermined power of 0.8. If practical restrictions are removed, allocating more replicates to the $\mathrm{n}_{-}$site than to the $\mathrm{n} \_$block is recommended. a: n_site $=4$ and n_block $=6$

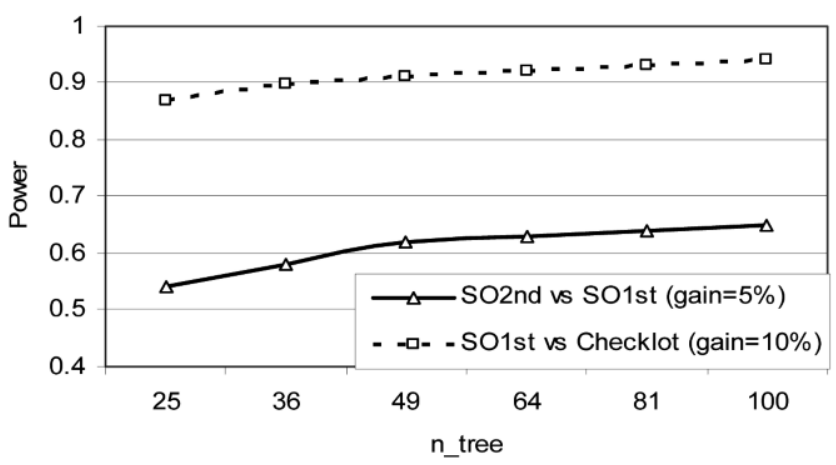

b: $n \_$site $=4$ and $n$ tree $=36$

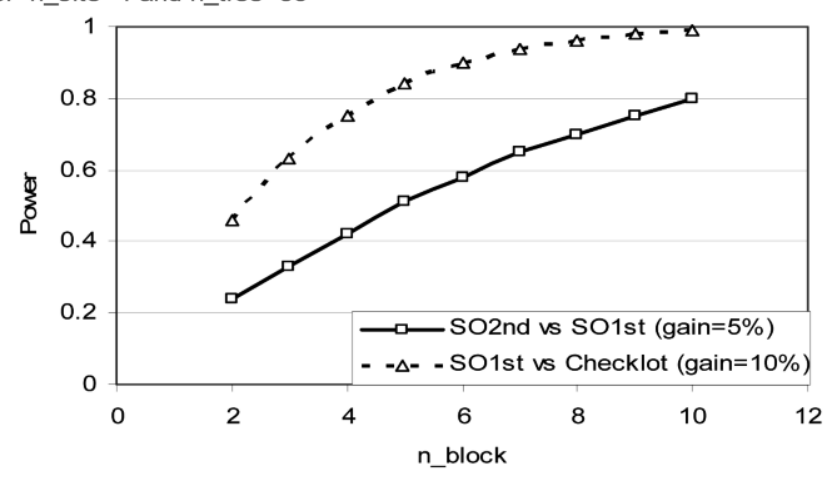

c: $n \_b l o c k=6$ and $n \_$tree $=36$

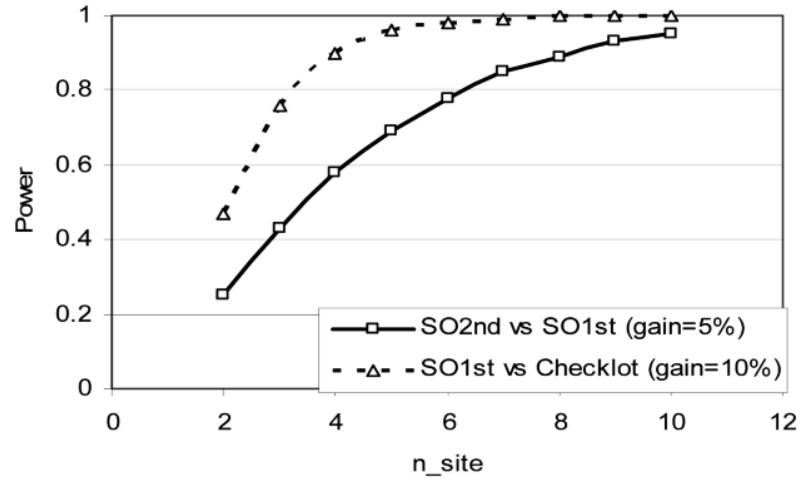

Figure 1. - Effects of the numbers of (a) trees per plot (n_tree), (b) blocks per site (n_block) and (c) sites (n_site) on power for comparing the $\mathrm{SO}_{1 \mathrm{st}}$ with the Checklot (gain=10\%) and comparing the $\mathrm{SO}_{2 \text { nd }}$ with $\mathrm{SO}_{1 \text { st }}$ (gain $=5 \%$ ). The analysis was done based on the variance component estimates for HT5 (Table 3). Note that a power of 0.8 means that the probability of observing a significant seedlot effect is approximately 0.8 .

Note that, the above testing effort distribution was obtained using the information from this specific test. Increasing the number of tested seedlots may improve the power as it increases the denominator degree of freedom for comparison. However, such an impact might not be substantial; doubling the number of tested seedlots in this study $(=5)$, the power for comparing $\mathrm{SO}_{2 \text { nd }}$ to $\mathrm{SO}_{1 \mathrm{st}}$ increased from 0.58 to 0.61 only. A realized gain test typical includes 3 to 6 seedlots, very unlikely to include more than 10. Furthermore, the variance component estimates for HT5 (Table 3) are similar to those of other NBTIC gain tests (WENG et al., 2008; 2010). Thus, these 
findings should provide a good guideline for establishing future NBTIC realized gain tests.

Calculating the power for planning a realized gain test requires tree breeders to know what to use for treatment differences (gains) and for variances. Finding typical gains for tree improvement programs is relatively easy; similar to this study, a gain from 5 to $10 \%$ in growth per generation is always assumed (ST. CLAIR et al., 2004). Finding typical variance component estimates, however, are difficult. Quite often, published variance component estimates are inconsistent, varying from test to test or species to species, and can only be applied to the specific tests/species. A power analysis of how to optimize testing efforts under various variance component estimates is essential. This was done by using the variance component estimates for HT5 (see Table 3 ) as the baseline scenario and varying one variance at a time. Whereas varying the site or block within site variance had none or little effects (data not shown), the BS and TS interaction variances showed substantial effects on the distribution of testing efforts. For a given power, a smaller BS interaction variance required small-

a: n_site $=4$ and n_tree $=36$

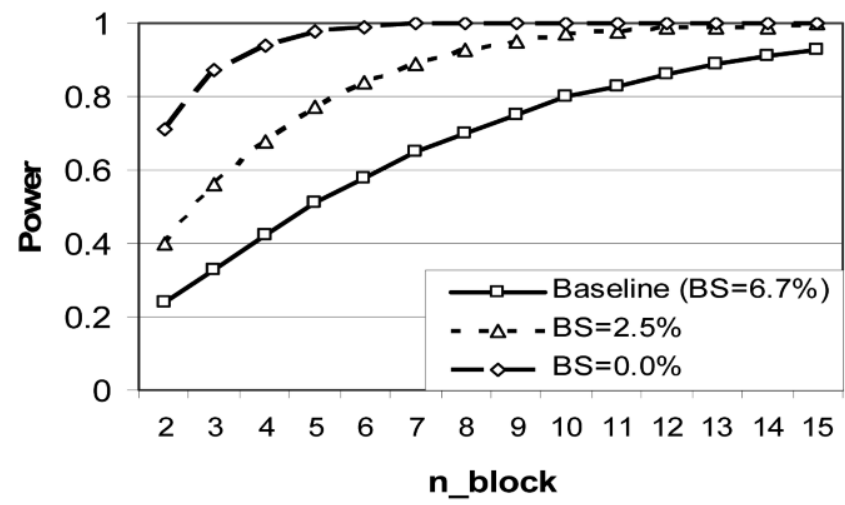

b: $n \_b l o c k=6$ and n_tree $=36$

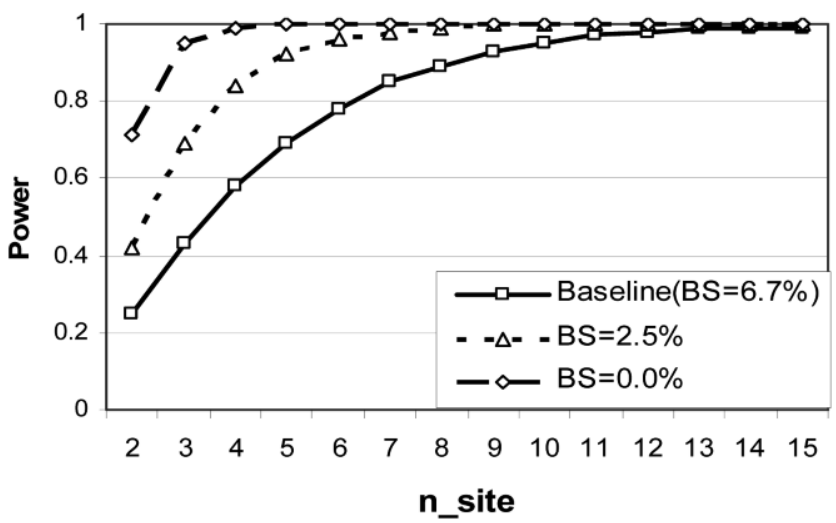

Figure 2. - Effects of seedlot and block (BS) interaction on power for comparing the $\mathrm{SO}_{2 \text { nd }}$ with $\mathrm{SO}_{1 \text { st }}$ (gain=5\%) under various testing effort distributions by varying the numbers of (a) blocks (n_block) and (b) sites (n_site). The variance components for HT5 (Table 3) was used as the baseline scenario where the BS interaction accounted for $6.7 \%$ of the total variation. The other scenarios were created by changing the interaction and error variances of the baseline so that the interaction accounted for $0.0 \%$ and $2.5 \%$ of the total variation.

\section{a: $n$ site $=4$ and $n$ tree $=36$}

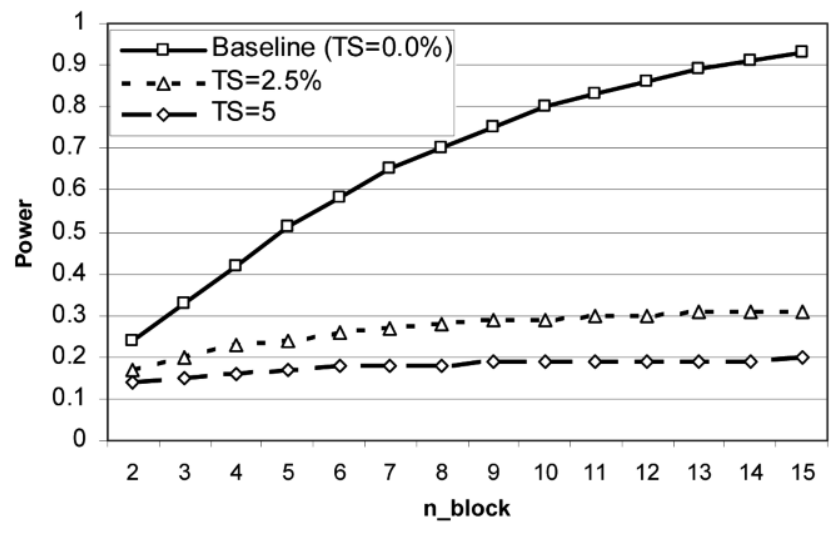

b: $n \_b l o c k=6$ and $n \_t r e e=36$

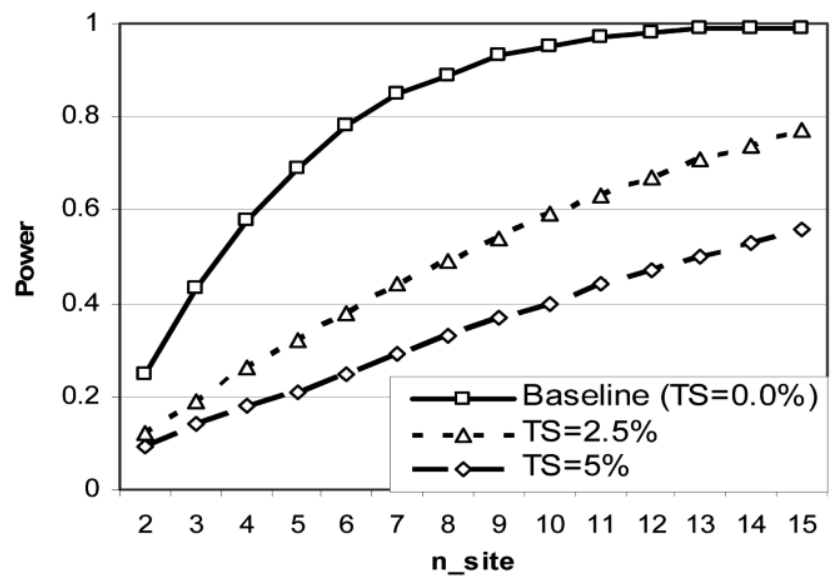

Figure 3. - Effects of seedlot and site (TS) interaction on power for comparing the $\mathrm{SO}_{2 \text { nd }}$ with $\mathrm{SO}_{1 \text { st }}$ (gain $=5 \%$ ) under various testing effort distributions by varying the numbers of (a) blocks (n_block) and (b) sites (n_site). The variance components for HT5 (Table 3) was used as the baseline where the TS interaction accounted for $0.0 \%$ of the total variation. The other scenarios were created by changing the interaction and error variances of the baseline so that the interaction accounted for $2.5 \%$ and $5.0 \%$ of the total variation.

er n_site or n_block (Figure 2). For example, to detect a significant $(\alpha=0.05)$ difference between the $\mathrm{SO}_{2 \text { nd }}$ and $\mathrm{SO}_{1 \mathrm{st}}($ gain $=5 \%$ ) with the predetermined power of $0.8,3$ blocks per site (n_site was fixed at 4 ) or 3 sites (n_block was fixed at 6) was required when the BS interaction variance was non-existent, compared with 10 blocks or 7 sites in the baseline scenario (the BS interaction variance was $6.7 \%$ of the total variation). When TS interaction was strong, the realistic way to improve power was to increase n_site (Figure 3). Over 15 sites were required to be planted for a test when the TS interaction accounted for $2.5 \%$ of the total variation if the objective was to obtain the predetermined power (0.8) for comparing the $\mathrm{SO}_{2 \text { nd }}$ and $\mathrm{SO}_{1 \mathrm{st}}$. These results suggest that much larger numbers of replicates are required if the interactions, in particular the TS interaction, are stronger. A significant and large TS interaction, however, would indicate breeding zones were poorly defined.

By setting a power of 0.80 and $\alpha=0.05$, ST. CLAIR et al. (2004) reported that 20 to 50 replicates are required to 
detect statistically significant differences in height between improved and unimproved populations given genetic gains of expected in a typical tree improvement program (from $5 \%$ to $10 \%$ ). How to further distribute the 20 to 50 replicates into the n_site and n_block was not investigated in their study. In this study, the required n_site, n_block and n_tree were calculated for the mixed model with multiple sources of variation, including interaction effects. Application of the results in this study seems straightforward, but practical restrictions due to the number and size of available sites are likely.

\section{Conclusions}

Two-cycle selection and breeding have produced substantial improvement in early height growth for black spruce in NB. Compared with the unimproved checklot, planting the improved seedlots would produce about $10 \%$ gain in HT5 for those collected from the first-generation seed orchards and 5\% more for those collected from the second-generation orchards. Deployment of some elite full-sib families would be much more effective in improving growth than via seed orchard seed. To establish a realized gain test so that typical gains (5 to $10 \%$ ) can be statistically detected with a predetermined power of $0.80,5$ to 10 blocks per site (n_site was fixed at 4) or 4 to 6 sites (n_block was fixed at 6) paired with planting 36 to 49 trees per plot are required in NBTIC programs. Application of these approximate numbers of sites and blocks per site in other programs should be considered, depending on the relative size of the interactions between seedlot and site and seedlot and block within a site.

\section{Acknowledgement}

I would like to express my appreciation to the dedicated NBTIC member agencies who contributed so much to the success of this program. Thank also went to DALE SIMPSON for editing.

\section{References Cited}

Andersson, B., B. Elfving, T. Ericsson, T. Persson and B. Gregorsson (2003): Performance of improved Pinus sylvestris in Northern Sweden. Scandinavian Journal of Forest Research 18: 199-206.

Carson, S. D., O. Garcia and J. D. Hayes (1999): Realized gain and prediction of yield with genetically improved Pinus radiata in New Zealand. Forest Science 45: 186-200.

Dhakal, L. P., T. L. White and G. R. Hodge (1996): Realized genetic gains from Slash pine tree improvement. Silvae Genetica 45: 190-197.

ELDRIDGE, K. E. (1982): Genetic improvements from a radiata pine seed orchard. New Zealand Journal of Forest Science 12: 404-411.

FOWLER, D. P. (1986): Strategies for the genetic improvement of important tree species in the Maritimes. Natural Resources Canada, Canadian Forest Service Atlantic Forestry Centre, Information Report M-X-156.
Gilmour, A. R., B. J. Gogel, B. R. Cullis, S. J. Welham and R. Thompson (2002): ASReml User Guide Release 1.0. VSN Interactional Ltd., Hemel Hempstead, HP11ES, UK. 267pp

KononofF, P. J. and K. J. HANFORD (2006): Estimating statistical power of mixed models used in dairy nutrition experiments. Journal of Dairy Science 89: 3968-3971.

Littell, R. C., G. A. Milliken, W. W. Stroup, R. D. WOlFINGER and O. SCHABENBERGER (2006): SAS for mixed models. $2^{\text {nd }}$ edition. SAS Institute Inc., Cary, NC, USA.

MATZIRIS, D. I. (2000): Genetic variation and realized genetic gain from Aleppo pine tree improvement. Silvae Genetica 49: 5-10.

McKeand, S. E., E. J. Jokela, D. A. Huber, T. D. Byram, H. L. Allen, B. Li and T. J. Mullin (2006): Performance of improved genotypes of loblolly pine across different soils, climates, and silvicultural inputs. Forest Ecology and Management 227: 178-184.

McKeand, S. E., B. J. Zobel, T. D. Byram and D. A. HUBER (2007): Southern pine tree improvement - A living success story. In: Proceeding of the $29^{\text {th }}$ Southern Forest Tree Improvement Conference. Tree Improvement in North America: Past, Present, and Future, WFGA/SFTIC Joint Meeting, Galveston, TX. June 19-22, 2007.

(NBTIC) New Brunswick Tree Improvement Council (1977): 1977 black spruce stand tests. 10- and 15-year measurements. NBTIC Establishment Report No. 1. Fredericton, New Brunswick.

SAS INSTITUTE INC. (1990): SAS procedures guide, version $6,3^{\text {rd }}$ edition. SAS Institute Inc., Cary, NC, USA. 705pp.

Staudhammer, C. L., E. J. Jokela and T. A. Martin (2009): Competition dynamics in pure-versus mixedfamily stands of loblolly and slash pine in the southeastern United States. Canadian Journal of Forest Research 39: 396-409.

St. Clair, J. B., N. L. MANDEL and K. J. S. JAYAWICKRAMA (2004): Early realized genetic gains for coastal Douglasfir in the Northern Oregon cascades. Western Journal of Applied Forestry 19: 195-201.

STRoup, W. W. (1999): Mixed model procedures to assess power, precision, and sample size in the design of experiments. Pages 15-24. In: Proceeding of Biopharmaceutical Section. American Statistic Association, Baltimore, MD.

Stoehr, M., K. Bird, G. Nigh, J. Woods and A. YanchuK (2010): Realized genetic gains in coastal Douglas-fir in British Columbia: Implications for growth and yield projections. Silvae Genetica 59: 223-233.

TALBERT, J. T. (1981): One generation of loblolly pine tree improvement: results and challenges. In: Proceeding of $18^{\text {th }}$ meeting of the Canadian Tree Improvement Association. Pp 106-120.

Vergara, R., T. L. White, D. A. Huber and R. A. Schmidt (2004): Estimated realized gains for first-generation slash pine (Pinus elliottii var. elliittii) tree improvement in the southeastern United States. Canadian Journal of Forest Research 34: 2587-2600.

Weng, Y. H., K. J. Tosh, G. Adam, M. S. Fullarton, C. NoRfolK and Y. S. PARK (2008): Realized genetic gains observed in a first generation seedling seed orchard for jack pine in New Brunswick, Canada. New Forests 36: 285-298. 
WenG, Y. H., K. J. Tosh and M. S. Fullarton (2010): Determining and projecting realized genetic gains: Results from early-stage spruce improvement programs in New Brunswick, Canada. New Zealand Journal of Forest Science 40: 5-17.

Ye, T. Z., K. J. S. JAYAWICKRAMA and J. B. ST. Clair (2010): Realized gains from block-plot coastal Douglas-fir trials in the northern Oregon Cascades. Silvae Genetica 59: 29-39.
ZELANZY, V. F. (2007): Our landscape heritage: the story of ecological land classification in New Brunswick. $2^{\text {nd }}$ edition. New Brunswick Department of Natural Resources, Fredericton, New Brunswick, Canada.

ZoBel, B. J. and J. T. TALBERT (1984): Applied forest tree improvement. John Wiley \& Sons. New York, USA. 505pp.

\title{
Comparison of French and German sessile oak (Quercus petraea (Matt.) Liebl.) provenances
}

\author{
By H. GrotehusmanN ${ }^{1)}$ and E. SchöNFELDER ${ }^{2)}$ \\ Nordwestdeutsche Forstliche Versuchsanstalt, Abteilung Forstgenressourcen, D-34346 Hann. Münden
}

(Received $16^{\text {th }}$ August 2010)

\begin{abstract}
Provenances originating from French and German sessile oak seed sources were analysed 23 years after planting at nine different locations in Northwest Germany. In general, German provenances are better adapted to the prevailing conditions of the test sites showing a better survival. Differences between the provenances in measured growth characters ("DBH", "height") were less pronounced than in observed quality parameters ("form", "crown"). Five of the German provenances showed a better stem form; only three French provenances exceeded the overall mean. Variation in phenotypic stability between provenances could be observed as well as rank changes of provenances measured at different ages. Observed variation in stability was mainly attributable to single provenances, however, no pattern of variation could be detected. Besides the German seed sources "Bundesgebiet", "Spessart" and "Göhrde" some French provenances ("Reno Valdieu", "Bertranges", "Darney" and "Der") can be recommended as substitute in low crop years.
\end{abstract}

Key words: Q. petraea, provenance, test, adaptation, stability.

\section{Introduction}

In Germany about 3306 seed stands of sessile oak are registered for harvesting, which cover an area of nearly 32.000 ha (FEDERAL OFFICE FOR AGRICUlTuRE AND FOOD 2008, available at www.ble.de). There is an average amount of harvested acorns of about 233 tons per year

1) Corresponding author: Helmut Grotehusmann, Nordwestdeutsche Forstliche Versuchsanstalt, Abteilung Waldgenressourcen, D-34346 Hann. Münden. E-mail: helmut.grotehusmann@nw-fva.de

2) EGBeRt SCHÖNFELDER, Nordwestdeutsche Forstliche Versuchsanstalt, Abteilung Waldwachstum, D-37079 Göttingen. over a ten-year period (FEDERAL OFFICE FOR AGRICULTURE AND FoOD 2010, available at www.ble.de). However, seed stands in Germany fructificate irregularly. Furthermore, the acorns cannot be stored for a sufficiently long time to bridge the gap between subsequent harvests. In order to provide sufficient seed and seedlings, research on optimal storage conditions of acorns (HOFFMANN, 1990; Guthke and SpethmanN, 1993; Liesebach and ZASPEL, 2004) or mass propagation of superior seedlings (JÖRGENSEN, 1994) has been done.

Oak stands of excellent quality grow in France and due to favourable climatic conditions, these stands often show a prolific seed production whereas in Germany only rare harvests are possible. In order to overcome local bottlenecks and to provide practical forestry with sufficient seedlings it would be interesting to know if French oaks were suitable for cultivation in Northern German.

Unfortunately, only little information was available about the performance of French provenances under German conditions. With the intention of getting more information associated with French provenances the former Lower Saxony Forest Research Institute established a provenance trial with provenances from French Quercus petraea stands. It was intended to compare French and German provenances under near practice conditions, so cultural treatments were comparable to the recommendations valid for practical forestry at the time of trial establishment

\section{Materials and Methods}

Seedlings from eleven French stands were obtained by the private German nursery Rahte, and as a basis of comparison, six German provenances and one progeny 